\title{
Design Considerations for a Scintillating Plate Calorimeter for SDC
}

\author{
Thomas Handler \\ Physics Dept. \\ University of Tennessee \\ Knoxville, Tenn 37996-1200

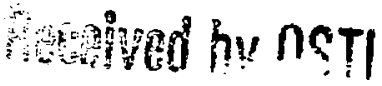 \\ P. K. Job \\ High Energy Physics Division \\ Argonne National Laboratory \\ Argonne, IIl 60439 \\ T. A. Gabriel \\ Engineering Physics and Mathemetics Division \\ Oak Ridge National Laboratory \\ Oak Ridge, Tenn 37831

\begin{abstract}
As scintillating plate calorimetry is a viable option for the SDC detector, it is imperative that the phase space of passive and active materials be explored in a systematic fashion. To this end, we have examined several different configurations of passive and active materials as a function of incident energy, to see what the resolution and $e / h$ characteristics are of each of these configurations. These studies have been carried out using the CALOR89 Monte Carlo simulation package.
\end{abstract}

\section{DISCLAIMER}

This report was prepared as an account of work sponsored by an agency of the United States Government. Neither the United States Government nor any agency thereof, nor any of their employees, makes any warranty, express or implied, or assumes any legal liability or responsibility for the accuracy, completeness, or usefulness of any information, apparatus, product, or process disclosed, or represents that its use would not infring: privately owned rights. Reference herein to any specific commercial product, process, or service by trade name, trademark, manufacturer, or otherwise does not necessarily constitute or imply its endorsement, recommendation, or favoring by the United States Government or any agency thereof. The views and opinions of authors expressed herein do not necessarily state or reflect those of the United States Government or any agency thereof.

This work supported in part by the U.S. Department of Energy, Division of High Energy Physics, Contract W-31-109-ENG-38.

\section{MASTER}




\section{Introduction}

Previous studies ${ }^{1}$ of scintillating plate calorimeters have been concerned with calorimeters that had uniform sampling and a single type of passive material throughout the calorimeter. The results of these calculations showed the following: 1) Lead gave resonable results for compensation and resolution. 2) Iron was shown to be unacceptable as far as its compensation characteristics were concerned. 3) Though depleted uranium had resonable resolution and compensation characteristics, its time structure was unacceptable, as up to $30 \%$ of the signal came in after 100ns.

In Table I we summarize the various configurations that have been examined using the CALOR89 simulation system. The calorimeter wus divided into three sections. The first section, a fine sampling electromagnetic section consisting of a lead/scintillator cell, was the same in the five configurations studied. What was varied amongst the five configurations was the composition and thickness of the passive material for the second and third segments. Three of the configurations had lead as the passive material in the second segment, while the other two had iron. The third segment was iron in all the configurations with the thickness of the iron being varied in the various configurations. In all configurations the thickness of the scintillator was held fixed at $0.25 \mathrm{~cm}$.

The presented results are for an integration time of 48 ns on the neutrons. No photostatistics or light collection efficiencies have been incorporated into the simulations. As each of the sections of the various configurations examined has a different sampling fraction, the energy that is deposited in a given scintillator in a given section is multiplied by the weighting factor for that section. This weighting factor is given by

$$
\text { weight }=\frac{\sum\left(\frac{d E}{d x}\right)_{i} \rho_{j}(\Delta x)_{i}}{\left(\frac{d E}{d x}\right)_{s c i n t} \rho_{s c i n t}(\Delta x)_{s c i n t}}
$$

The sum runs over the materials in the given section.

For a given configuration and energy, the hadronic signal is derived by adding the energy deposition as determined in the prograrns SPECT, EGS, and

1'CALOR89 Calorimeter Simulations, Benchmarking, and Design Calculations,' Submitted to Symposium on Detector Research and Development for the Superconducting Super Collider, Ft. Worth, TX OCt 15-12, 1990.

'Simulation Studies for Design Optimisation of a Scintillator Plate Calorimeter,' Submitted to Symposium on Detector Research and Development for the Superconducting Super Collider, Ft. Worth, TX OCt 15-12, 1990. 
MORSE, which are part of the CALOR89 code system, on an event by event basis. This energy deposition was then histogramed. Then a gaussian fit to the histogram was performed to determine the mean energy deposition and its standard deviation. From these quantities the various resolutions were determined. For a given configuration, the resolution data points at the different energies were then fit, by chisquare methods, to a function of the form

$$
\left(\frac{\sigma}{E}\right)^{2}=\frac{a^{2}}{E}+b^{2} \text {. }
$$

\section{Electromagnetic Resolution}

The electromagnetic resolution was fairly indepencent of the configuration simulated. This is primarily due to the fact that electrons were almost totally absorbed by the first segment. The energy absorption ranged from a low of $95 \%$ at an energy of $125 \mathrm{GeV}$ to a high of $98 \%$ at $10 \mathrm{GeV}$. The differences in resolution are therefore due to the variation of the second segment. The results of chisquare fits to the resolution function are presented in Table II. The resolution curves for the various configurations are presented in Figure 1.

\section{Hadronic Resolution}

The hadronic resolution is dependent upon both the composition and thickness of the passive material used in the second segment. When either the

- thickness of the lead was increased in the second segment (AUGO2), or the lead was replaced with iron (AUG03 and AUG04), the resolution worsened, both in terms of the coefficient of the energy dependent term end the constant term. When the lead thickness in the second segment was kept the same as in AUG01 and with the iron thickness increased in the third segment(AUGO5), the resolution barely changed with respect to the coefficient and ihe constant term, as determined in AUG01. The results of chisquare fits to the resolution function are presented in Table III. The hadronic resolution curves for the various configurations are presented in Figure 2.

$\underline{e / h}$

The $e / h$ ratio is dichotomous, as can be seen in Figure 3 . Those configurations wherein lead was used in the second segment have $\mathrm{e} / \mathrm{h}$ values which stay above 1.0 and ere relatively constant over the energy range examined, while those coniigurations using iron in the second segment are not constant with energy and also drop below 1.0 as the incident energy increases. The e/h values are presented in Table IV. 
If photostatistics and light collection efficiencies were included in the simulation, this would tend to decrease the hadronic signal relative to the electromagnetic signal. This would then drive all $\mathrm{e} / \mathrm{h}$ to higher values.

\section{Conclusions}

If we were to pick one of these configurations as the final design choice, we would recommend that either AUG01 or AUG05 be used for two reasons: 1) the better resolution and lower value for the constant term, and 2) the relative constancy of $e / h$. On the basis of hadronic punch through, Table $V$, and the number of channels, we would recommend AUG05 be used. 
Table I. Configurations Simulated

\begin{tabular}{|c|c|c|c|}
\hline AUG01 & & & \\
\hline & Pb/Scint & $\mathrm{Pb} /$ Scint & Fe/Scint \\
\hline Thicknesses & $0.55 / 0.25$ & $1.55 / 0.25$ & $3.55 / 0.25$ \\
\hline \# cells & 20 & 34 & 27 \\
\hline AUGO2 & & & \\
\hline & $\mathrm{Pb} /$ Scint & $\mathrm{Pb} / \mathrm{Scint}$ & Fe/Scint \\
\hline Thicknesses & $0.55 / 0.25$ & $3.55 / 0.25$ & $7.55 / 0.25$ \\
\hline \# cells & 20 & 15 & 13 \\
\hline AUG03 & & & \\
\hline & $\mathrm{Pb} / \mathrm{Scint}$ & $\mathrm{Fe} / \mathrm{Scint}$ & $\mathrm{Fe} / \mathrm{Scint}$ \\
\hline Thicknesses & $0.55 / 0.25$ & $3.55 / 0.25$ & $3.55 / 0.25$ \\
\hline \# cells & 20 & 15 & 27 \\
\hline AUGO4. & & & \\
\hline & $\mathrm{Pb} / S c i n t$ & Fe/Scint & Fe/Scint \\
\hline Thicknesses & $0.55 / 0.25$ & $3.55 / 0.25$ & $7.55 / 0.25$ \\
\hline \# cells & 20 & 15 & 13 \\
\hline AUG05 & & & \\
\hline & $\mathrm{Pb} /$ Scint & $\mathrm{Pb} /$ Scint & Fe/Scint \\
\hline Thicknesses & $0.55 / 0.25$ & $1.55 / 0.25$ & $7.55 / 0.25$ \\
\hline \# cells & 20 & 34 & 13 \\
\hline
\end{tabular}


Table II. Electromagnetic Resolution Results

\begin{tabular}{|l|c|c|}
\cline { 2 - 3 } \multicolumn{1}{c|}{} & $\mathrm{a}$ & $\mathrm{b}$ \\
\hline AUG01 & $0.1786+/-0.0068$ & $0.0027+/-0.0095$ \\
AUG02 & $0.1747+/-0.0120$ & $0.0096+/-0.0023$ \\
AUG03 & $0.1788+/-0.0094$ & $0.0083+/-0.0024$ \\
AUG04 & $0.1786+/-0.0071$ & $0.0084+/-0.0045$ \\
AUG05 & $0.1676+/-0.0114$ & $0.0076+/-0.0028$ \\
\hline
\end{tabular}

Table III. Hadronic Resolution Results

\begin{tabular}{|l|c|c|}
\cline { 2 - 3 } \multicolumn{1}{c|}{} & a & b \\
\hline AUG01 & $0.5164+/-0.0244$ & $0.0271+/-0.0078$ \\
AUG02 & $0.6685+/-0.0449$ & $0.0542+/-0.0098$ \\
AUG03 & $0.7589+/-0.0434$ & $0.0788+/-0.0084$ \\
AUG04 & $0.7443+/-0.0514$ & $0.1023+/-0.0094$ \\
AUG05 & $0.5262+/-0.0234$ & $0.0211+/-0.0086$ \\
\hline
\end{tabular}


Table IV. e/h Values

\begin{tabular}{|l|c|c|c|c|}
\cline { 2 - 5 } \multicolumn{1}{c|}{} & $10 \mathrm{GeV}$ & $30 \mathrm{GeV}$ & $75 \mathrm{GeV}$ & $125 \mathrm{GeV}$ \\
\hline AUG01 & $1.054+/-0.011$ & $1.017+/-0.006$ & $1.023+/-0.005$ & $1.005+/-0.005$ \\
AUG02 & $1.068+/-0.014$ & $1.010+/-0.010$ & $1.019+/-0.006$ & $1.011+/-0.007$ \\
AUG03 & $1.068+/-0.016$ & $0.967+/-0.010$ & $0.899+/-0.007$ & $0.898+/-0.008$ \\
AUG05 & $1.115+/-0.016$ & $0.979+/-0.011$ & $0.926+/-0.008$ & $0.928+/-0.012$ \\
\hline
\end{tabular}

Table V. Punch Through

\begin{tabular}{|l|l|l|l|l|}
\cline { 2 - 5 } \multicolumn{1}{c|}{} & \multicolumn{1}{c|}{$10 \mathrm{GeV}$} & \multicolumn{1}{c|}{$30 \mathrm{GeV}$} & \multicolumn{1}{c|}{$75 \mathrm{GeV}$} & $125 \mathrm{GeV}$ \\
\hline AUG01 & $0.014 \mathrm{GeV}$ & $0.222 \mathrm{GeV}$ & $0.718 \mathrm{GeV}$ & $1.639 \mathrm{GeV}$ \\
AUG02 & $0.023 \mathrm{GeV}$ & $0.069 \mathrm{GeV}$ & $0.812 \mathrm{GeV}$ & $1.388 \mathrm{GeV}$ \\
AUG03 & $0.012 \mathrm{GeV}$ & $0.194 \mathrm{GeV}$ & $0.787 \mathrm{GeV}$ & $1.385 \mathrm{GeV}$ \\
AUG04 & $0.009 \mathrm{GeV}$ & $0.169 \mathrm{GeV}$ & $0.802 \mathrm{GeV}$ & $1.437 \mathrm{GeV}$ \\
AUG05 & $0.022 \mathrm{GeV}$ & $0.119 \mathrm{GeV}$ & $0.401 \mathrm{GeV}$ & $1.093 \mathrm{GeV}$ \\
\hline
\end{tabular}




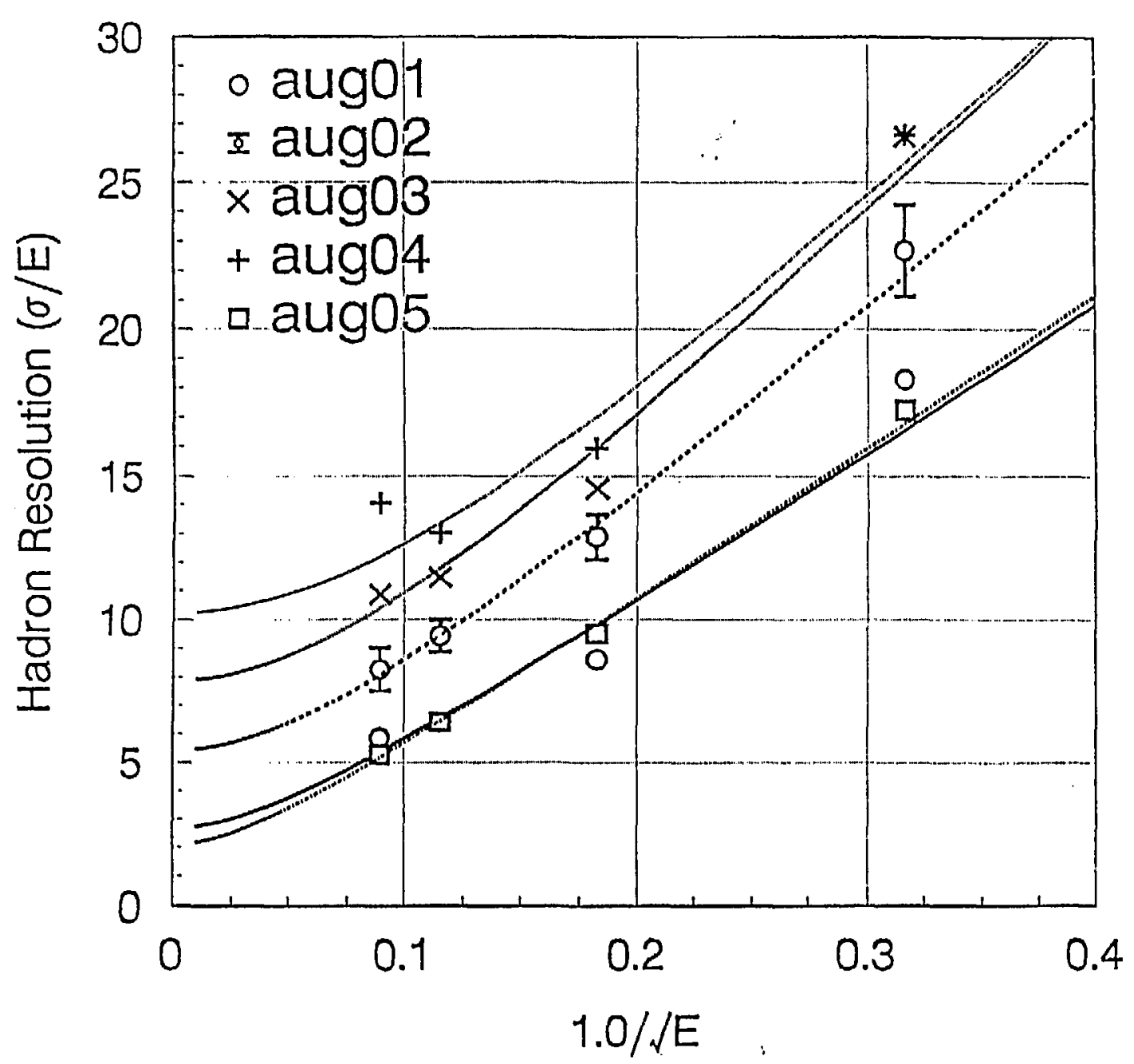

Figure 2. Hadronic Resolution for the various configurations simulated. The curves are the results of chisquare fits to the data points. The resultant parameters are detailed in Table III. 


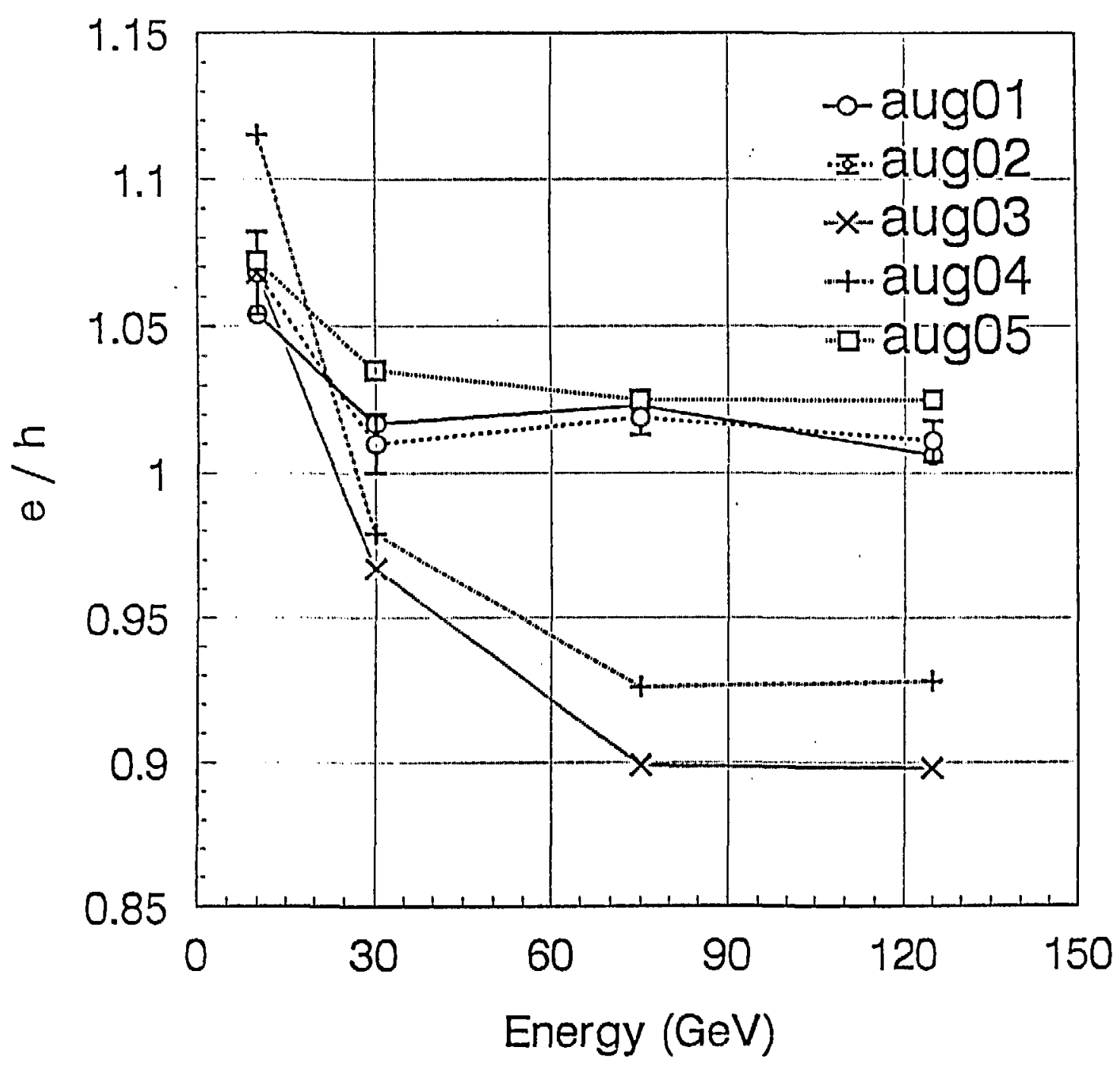

Figure 3. e/h as a function of energy for the different configurations. 